\title{
Adenosine stress native T1 mapping in severe aortic stenosis: evidence for a role of the intravascular compartment on myocardial T1 values
}

Masliza Mahmod ${ }^{1 *}$, Stefan K Piechnik ${ }^{1}$, Eylem Levelt ${ }^{1}$, Vanessa M Ferreira ${ }^{1}$, Jane M Francis ${ }^{1}$, Andrew Lewis ${ }^{1}$, Nikhil Pal ${ }^{1}$, Sairia Dass ${ }^{1}$, Houman Ashrafian'1 , Stefan Neubauer ${ }^{1}$ and Theodoros D Karamitsos ${ }^{1,2}$

\begin{abstract}
Background: Myocardial T1 relaxation times have been reported to be markedly abnormal in diverse myocardial pathologies, ascribed to interstitial changes, evaluated by T1 mapping and calculation of extracellular volume (ECV). T1 mapping is sensitive to myocardial water content of both intra- and extracellular in origin, but the effect of intravascular compartment changes on $\mathrm{T} 1$ has been largely neglected. We aimed to assess the role of intravascular compartment on native (pre-contrast) $\mathrm{T} 1$ values by studying the effect of adenosine-induced vasodilatation in patients with severe aortic stenosis (AS) before and after aortic valve replacement (AVR).

Methods: 42 subjects (26 patients with severe AS without obstructive coronary artery disease and 16 controls) underwent cardiovascular magnetic resonance at $3 \mathrm{~T}$ for native T1-mapping (ShMOLLI), first-pass perfusion (myocardial perfusion reserve index-MPRI) at rest and during adenosine stress, and late gadolinium enhancement (LGE).

Results: AS patients had increased resting myocardial T1 (1196 \pm 47 ms vs. $1168 \pm 27 \mathrm{~ms}, p=0.037$ ), reduced MPRI $(0.92 \pm 0.31$ vs. $1.74 \pm 0.32, p<0.001)$, and increased left ventricular mass index (LVMI) and LGE volume compared to controls. During adenosine stress, T1 in AS was similar to controls (1240 $\pm 51 \mathrm{~ms}$ vs. $1238 \pm 54 \mathrm{~ms}, \mathrm{p}=0.88$ ), possibly reflecting a similar level of maximal coronary vasodilatation in both groups. Conversely, the $T 1$ response to stress was blunted in AS ( $\Delta T 13.7 \pm 2.7 \%$ vs. $6.0 \pm 4.2 \%$ in controls, $p=0.013)$. Seven months after AVR $(n=16)$ myocardial T1 and response to adenosine stress recovered towards normal. Native T1 values correlated with reduced MPRI, aortic valve area, and increased LVMI.
\end{abstract}

Conclusions: Our study suggests that native myocardial $\mathrm{T1}$ values are not only influenced by interstitial and intracellular water changes, but also by changes in the intravascular compartment. Performing T1 mapping during or soon after vasodilator stress may affect ECV measurements given that hyperemia alone appears to substantially alter T1 values.

Keywords: Adenosine vasodilator, Intravascular compartment, Myocardial T1, Perfusion reserve, T1 mapping

\footnotetext{
* Correspondence: masliza.mahmod@cardiov.ox.ac.uk

'University of Oxford Centre for Clinical Magnetic Resonance Research (OCMR), Division of Cardiovascular Medicine, Radcliffe Department of Medicine, John Radcliffe Hospital, Oxford OX3 9DU, UK

Full list of author information is available at the end of the article
} 


\section{Background}

Myocardial T1 determination using cardiovascular magnetic resonance (CMR) is a technique that can be used to provide a quantitative measure of myocardial water, without the need for exogenous contrast agents [1]. Native (pre-contrast) T1 values are elevated in conditions associated with increased myocardial water content such as acute myocardial infarction [2,3], oedema [4], acute myocarditis [5] and Takotsubo cardiomyopathy [6]. T1 values have also been shown to be elevated in conditions associated with myocardial fibrosis and expanded interstitial space such as dilated cardiomyopathy, hypertrophic cardiomyopathy [7] and aortic stenosis [8]. Other conditions associated with $\mathrm{T} 1$ changes are protein deposition in amyloid (increased T1 values) [9], and lipid deposition in Anderson-Fabry disease [10] and iron deposition due to hemorrhage (low T1 values) [11].

Despite the rapidly growing applications, the T1 sensitivity to detect disease is not fully understood and the measurements depend somewhat on the particular choice of methods [12-14]. In particular, the documented native T1 elevation in diffuse fibrosis cannot originate directly from collagen itself, which in large enough concentrations would tend to reduce T1 similarly to other proteins [15]. Thus, the observed increase in native $\mathrm{T} 1$ values may be due to increase in tissue water content independently of its extra/intracellular or intra/extravascular origin. However, the influence of intravascular water volume to the T1 values has never been investigated before, either in normal or pathological conditions.

In this work, we aimed to examine the impact of induced vasodilatation on the native $\mathrm{T} 1$ values following adenosine stress perfusion. This allowed assessment of the potentially reduced vascular reactivity in AS due to coronary microvascular dysfunction [16]. We also investigated if these changes were reversible after aortic valve replacement (AVR). We hypothesized that T1 values depend on the degree of coronary vascular recruitment and would increase under adenosine stress perfusion, and that the response would be blunted in AS when compared to normal.

\section{Methods}

\section{Study population}

We prospectively recruited 26 patients with severe AS without obstructive coronary artery disease (CAD) on invasive coronary angiography scheduled prior to AVR. Severe AS was diagnosed based on the previously established criteria [17]. Briefly patients were included if the aortic valve area (AVA) was $\leq 1.0 \mathrm{~cm}^{2}$, peak aortic valve gradient was $64 \mathrm{mmHg}$ and there was no other significant valvular pathology on echocardiogram. Patients were excluded if they had systolic blood pressure (BP) $>160 \mathrm{mmHg}$ and diastolic $\mathrm{BP}>90 \mathrm{mmHg}$, LVEF $<50 \%$, contraindications to CMR, glomerular filtration rate $<60 \mathrm{ml} / \mathrm{min}$, underlying cardiomyopathy or known history of CAD. Of these patients, 16 had a repeat CMR scan 7 months after AVR. Ten patients did not have a follow-up scan due to reasons such as death (2 patients), pacemaker implantation (1 patient), hospital admission due to unrelated to cardiac causes (1 patient), lost to follow-up (3 patients) and declined a repeat scan (3 patients). In addition, healthy volunteers with no prior cardiac history or known cardiac risk factors, not on any cardiovascular medications and with a normal ECG served as controls. All subjects gave written informed consent to participate in the study and ethical approval from the National Research Ethics Service committee South Central - Berkshire was granted for all study procedures.

\section{Cardiovascular magnetic resonance}

CMR was performed in a 3 Tesla MR system (TIM Trio; Siemens Healthcare, Erlangen, Germany). Study participants were instructed to avoid caffeine-containing food and drinks for at least 24 hours prior to CMR scan. Cine imaging was performed using standard methods [18]. At rest, 3 short-axis images of T1 maps were acquired using the shortened modified look-locker inversion recovery (ShMOLLI) sequence as previously described [19]. Adenosine stress perfusion imaging was performed as previously described [20,21]. Briefly, adenosine $(140 \mu \mathrm{g} / \mathrm{kg} / \mathrm{min})$ was infused intravenously for at least 3 minutes, followed by acquisition of a single mid-ventricular slice (identical to the one acquired at rest) of T1 map. Then stress perfusion imaging was performed immediately after stress T1 imaging, using a bolus a gadolinium-based contrast (Gadodiamide, Omniscan; GEHealthcare) at a dose of $0.03 \mathrm{mmol} / \mathrm{kg}$ followed by a saline flush. After discontinuing adenosine, rest perfusion images were acquired 20 minutes after the stress study to allow sufficient time for contrast washout. For late gadolinium enhancement (LGE), an additional bolus of $0.1 \mathrm{mmol} / \mathrm{kg}$ gadodiamide was administered (total dose: $0.16 \mathrm{mmol} / \mathrm{kg}$ ) immediately after rest perfusion. The LGE images were acquired as previously described [22].

\section{Cardiac magnetic resonance image analysis}

Analysis of cardiac volumes, function and mass was performed according to the standard methods [18]. AVA was measured from direct planimetry in cine imaging. Information on the peak aortic valve gradient was obtained from the clinical echocardiogram performed as part of routine clinical care. For the analysis of ShMOLLI T1maps, the LV myocardium of the mid-axial slice acquired at baseline was contoured by a blinded observer (EL) using dedicated software, as previously described [6] providing a single average myocardial $\mathrm{T} 1$ value per each individual. The average values were also calculated after manually excluding areas with focal LGE. The myocardial T1 value from the stress mid-ventricular ShMOLLI T1 
map was obtained and compared to the $\mathrm{T} 1$ at baseline. For perfusion analysis, briefly, 3 contours (epicardial, endocardial and LV blood pool) were drawn on a single image and propagated throughout the perfusion series. The myocardium was divided into segments based on the American Heart Association (AHA) segmentation model. Signal intensity (SI) versus time curves were generated and normalized to the left ventricular (LV) blood pool upslope. Myocardial perfusion reserve index (MPRI) was defined as the ratio of stress to rest relative upslope, as previously described [23]. LGE quantification was performed using cmr42 software (version 4.0, Circle Cardiovascular Imaging) by a blinded observer (AL). The full-width-half-maximum (FWHM) technique was used to quantify fibrosis as previously described [24]. The volume of focal fibrosis was expressed as the LGE mass (g) and also as a percentage of total myocardial mass.

\section{Statistical analysis}

All data are expressed as mean \pm standard deviation or median (interquartile range), and checked for normality using Kolmogorov-Smirnov test. Categorical data are presented as numbers and percentages. Comparisons between the 2 groups were performed using Student $t$-test, the chi-square test, or Fisher's exact test as appropriate. Bivariate correlations were performed using Pearson's or Spearman's method as appropriate. Comparisons between pre- and post-AVR measurements in AS patients and rest and stress $\mathrm{T} 1$ values were performed using 2-tailed paired $t$-test. Comparisons between AS patients and controls at baseline and post-AVR were performed using Student $t$-test or Mann-Whitney $\mathrm{U}$ test as appropriate. A $P$-value $<0.05$ was considered significant. All statistical analyses were performed with IBM SPSS Statistics, version 20 .

\section{Results}

\section{Baseline study characteristics}

Patient characteristics during the baseline examination are summarized in Table 1. There were no significant differences in age, sex, body mass index, BP and pulse rate from controls. In the AS group 38\% were hypertensive but their BP were well controlled. There were a small number of diabetics (15\%) in the AS patient group, but their blood glucose and lipid levels were similar to the controls (results not shown).

\section{Assessment of left ventricular mass, function, focal fibrosis and myocardial T1}

CMR results are also summarized in Table 1. AS patients had significantly higher LVMI and LV ejection fraction when compared to controls. There was high burden of myocardial fibrosis in AS patients (absolute volume of focal fibrosis $29.3 \mathrm{~g}$, IQR $16.8-58.8 \mathrm{~g}$; \% LV
Table 1 Baseline clinical characteristics of severe AS patients and normal controls

\begin{tabular}{|c|c|c|c|}
\hline & $\begin{array}{l}\text { Severe aortic } \\
\text { stenosis } \\
(n=26)\end{array}$ & $\begin{array}{l}\text { Normal } \\
\text { controls } \\
(n=16)\end{array}$ & $P$ value \\
\hline Age (years) & $67.8 \pm 9$ & $63.3 \pm 3.4$ & 0.06 \\
\hline Male, n (\%) & $19(73)$ & $8(53)$ & 0.16 \\
\hline \multicolumn{4}{|l|}{ Past medical history, n (\%) } \\
\hline Hypertension & $10(38)$ & - & \\
\hline Diabetes & $4(15)$ & - & \\
\hline \multicolumn{4}{|l|}{ Medications, n (\%) } \\
\hline Metformin & $4(15)$ & - & \\
\hline ACE-I/ARB-II & $7(27)$ & - & \\
\hline Beta-blockers & $5(19)$ & - & \\
\hline Body mass index $\left(\mathrm{kg} / \mathrm{m}^{2}\right)$ & $27.8 \pm 4.5$ & $27.0 \pm 3.8$ & 0.38 \\
\hline $\begin{array}{l}\text { Systolic blood pressure } \\
(\mathrm{mmHg})\end{array}$ & $134.4 \pm 18.1$ & $131.0 \pm 11.0$ & 0.51 \\
\hline $\begin{array}{l}\text { Diastolic blood pressure } \\
(\mathrm{mmHg})\end{array}$ & $74.4 \pm 9.4$ & $76.5 \pm 10.2$ & 0.51 \\
\hline Heart rate (bpm) & $66.1 \pm 9.4$ & $64.3 \pm 10.5$ & 0.58 \\
\hline Peak AV gradient $(\mathrm{mmHg})^{*}$ & $83.1 \pm 14.6$ & - & \\
\hline \multicolumn{4}{|l|}{ CMR findings } \\
\hline Aortic valve area $\left(\mathrm{cm}^{2}\right)$ & $0.82 \pm 0.02$ & $4.04 \pm 0.75$ & $<0.001$ \\
\hline LV end-diastolic volume (ml) & $143.2 \pm 44.4$ & $133.7 \pm 33.1$ & 0.47 \\
\hline LV ejection fraction (\%) & $74.5 \pm 5.8$ & $68.8 \pm 6.4$ & 0.005 \\
\hline LV mass index $\left(\mathrm{g} / \mathrm{m}^{2}\right)$ & $96.0 \pm 31.2$ & $55.8 \pm 13.9$ & $<0.001$ \\
\hline Presence of LGE, n (\%) & $21(81)$ & 0 & $<0.001$ \\
\hline Myocardial T1 (ms) & $1196 \pm 47$ & $1168 \pm 27$ & 0.037 \\
\hline
\end{tabular}

Values are mean $\pm S D$ or percentages. ACE indicates angiotensin-converting enzyme-inhibitors; ARB, angiotensin-receptor antagonist-II; LGE, CMR, cardiovascular magnetic resonance; late gadolinium enhancement; LV, left ventricular.

*Based on echocardiogram

mass $18.3 \pm 9.4 \%)$. None of the controls had LGE. As previously reported [8], native myocardial T1 was significantly higher in AS patients when compared to normal controls and remained elevated after excluding the areas with focal LGE $(1199 \pm 46 \mathrm{~ms}, \mathrm{p}=0.025$ vs. normal controls).

\section{Myocardial T1 and perfusion reserve under adenosine vasodilator stress}

Both AS patients and controls had equivalent rises in rate pressure product (RPP) during adenosine stress (baseline $8800 \pm 1600 \mathrm{mmHg} \cdot$ beats/min in AS vs. $8100 \pm$ $1500 \mathrm{mmHg} \cdot$ beats $/ \mathrm{min}$ in controls, $\mathrm{p}=0.19$ ) and (stress $11,400 \pm 2500 \mathrm{mmHg} \cdot$ beats $/ \mathrm{min}$ in AS vs. $11800 \pm$ $2800 \mathrm{mmHg}$. beats $/ \mathrm{min}$ in controls, $\mathrm{p}=0.69$ ).

Importantly we now report that $\mathrm{T} 1$ values were significantly increased during adenosine stress in both AS patients (from $1196 \pm 47 \mathrm{~ms}$ to $1240 \pm 51 \mathrm{~ms}, \mathrm{p}<0.001$ ) 
and normal controls (from $1168 \pm 27 \mathrm{~ms}$ to $1238 \pm$ $54 \mathrm{~ms}, \mathrm{p}<0.001)$. Interestingly, both groups exhibited similar maximal T1 values during adenosine stress (1240 \pm $55 \mathrm{~ms}$ in AS vs. $1238 \pm 54 \mathrm{~ms}$ in normal controls, $\mathrm{p}=0.90$ ). Given the T1 increase at rest, the stress response was blunted in AS patients, as expressed by significantly smaller absolute $\Delta \mathrm{T} 1(44 \pm 33 \mathrm{~ms}$ in AS vs. $70 \pm 49 \mathrm{~ms}$ in normal controls, $\mathrm{p}=0.013)$ and percentage of $\Delta \mathrm{T} 1(3.7 \pm$ $2.7 \%$ in AS vs. $6.0 \pm 4.2 \%$ in normal controls, $\mathrm{p}=0.013$ ). As expected, myocardial perfusion reserve was significantly reduced in AS patients when compared to normal controls (MPRI $0.92 \pm 0.31$ vs. $1.74 \pm 0.32, \mathrm{p}<0.001)$.

\section{Relationship amongst T1 values, perfusion and focal fibrosis (LGE) \\ Resting $T 1$}

Resting T1 values increased with increasing LVMI ( $r=0.59$, $\mathrm{p}<0.001)$ and absolute LGE volume $(r=0.46, \mathrm{p}=0.03)$ but not LGE volume as \% of LV mass $(\mathrm{r}=0.41, \mathrm{p}=0.066)$. Furthermore, $\mathrm{T} 1$ values had an inverse correlation with MPRI $(r=-0.51, \mathrm{p}=0.001)$ and AVA $(-0.35, \mathrm{p}=0.026)$. These relationships and their significance were preserved when the correlation analysis was repeated excluding segments showing focal LGE (results not shown).

\section{Stress $T 1$}

Stress T1 values had no significant correlations with LVMI, MPRI or LGE. The degree of stress T1 response $(\% \Delta \mathrm{T} 1)$ showed weak negative correlation with LVMI but no significant correlation with MPRI or LGE.

\section{Cardiac MRI post AVR $(n=16)$}

These results are summarized in Table 2. As expected, there was substantial reduction of LVH and improvement in perfusion reserve 7 months following AVR. There was

Table 2 CMR and before and after AVR $(n=16)$

\begin{tabular}{llll}
\hline & Pre AVR & Post AVR & Normal \\
\hline Myocardial T1 (ms) & $1197 \pm 35$ & $1167 \pm 43^{*}$ & $1168 \pm 27$ \\
$\begin{array}{l}\text { Stress myocardial } \\
\text { T1 (ms) }\end{array}$ & $1241 \pm 44$ & $1237 \pm 53^{\dagger}$ & $1238 \pm 54$ \\
$\Delta \mathrm{T} 1$ (\%) & $3.7 \pm 2.9$ & $6.0 \pm 2.0^{*}$ & $6.0 \pm 4.2$ \\
$\begin{array}{l}\text { Myocardial perfusion } \\
\text { reserve index }\end{array}$ & $0.97 \pm 0.38$ & $1.63 \pm 0.56^{*}$ & $1.74 \pm 0.32$ \\
$\begin{array}{l}\text { Left ventricular mass } \\
\left.\text { index (g/m }{ }^{2}\right)\end{array}$ & $97.4 \pm 29.0$ & $68.8 \pm 16.4^{*}$ & $55.8 \pm 13.9$ \\
$\begin{array}{l}\text { Absolute LGE } \\
\text { Mass (g) }\end{array}$ & $25.0(14.9-54.3)$ & $17.3(13.6-30.4)^{* *}$ & - \\
LGE \% of myocardium (\%) & $17.5 \pm 10.6$ & $16.4 \pm 10.8^{* * *}$ & -
\end{tabular}

Values are mean $\pm S D$ or median (interquartile range). LGE indicates late gadolinium enhancement.

${ }^{*} p<0.05$ vs pre AVR and $>0.05$ vs normal; $+p>0.05$ vs pre AVR and normal; $\neq \mathrm{p}<0.05$ vs pre AVR and normal; ${ }^{* *} \mathrm{p}<0.05$ vs pre AVR; ${ }^{* * *} \mathrm{p}>0.05$ vs pre AVR. LGE data were based on $n=14$ who had LGE + . significant reduction in resting $\mathrm{T} 1$ values post AVR with no significant difference compared to controls. More importantly, the diminished T1 response to adenosine stress pre-AVR improved significantly to normal level post-AVR (Figures 1 and 2), as shown by an increase in T1 reactivity (absolute $\Delta \mathrm{T} 144 \pm 34 \mathrm{~ms}$ pre-AVR to $70 \pm 24 \mathrm{~ms}$ post$A V R, p=0.02$ [paired $\mathrm{t}$ test for $\mathrm{n}=16$ ]; post-AVR $\Delta \mathrm{T} 1 \mathrm{vs}$. controls, $\mathrm{p}=0.57$ ). Examples of CMR images of a patient with severe AS pre and post AVR and a normal control are shown in Figure 3. The absolute volume of focal fibrosis decreased post-AVR, but the percentage LV myocardium that showed fibrosis was unchanged compared to pre-AVR.

\section{Discussion}

Increased myocardial $\mathrm{T} 1$ values has previously been linked to expansion of interstitial space owing to interstitial fibrosis based on native T1 and ECV measurements using post-contrast T1 techniques [25,26]. In this study, we confirm that resting myocardial $\mathrm{T} 1$ values are elevated in severe AS patients compared to normal controls and correlate with markers of disease severity, such as aortic valve area, LVH [8], and myocardial perfusion reserve. We have shown for the first time that $\mathrm{T} 1$ values in both AS patients and normal controls increase in response to adenosine vasodilator stress. Interestingly, the achieved level of maximal stress $\mathrm{T} 1$ was the same in AS patients as in controls, with blunted stress $\mathrm{T} 1$ response (reduced $\Delta \mathrm{T} 1$ ) in $\mathrm{AS}$ owing to higher resting $\mathrm{T} 1$. Importantly, the abnormal resting myocardial $\mathrm{T} 1$ and the reduced $\Delta \mathrm{T} 1$ stress response normalized seven months

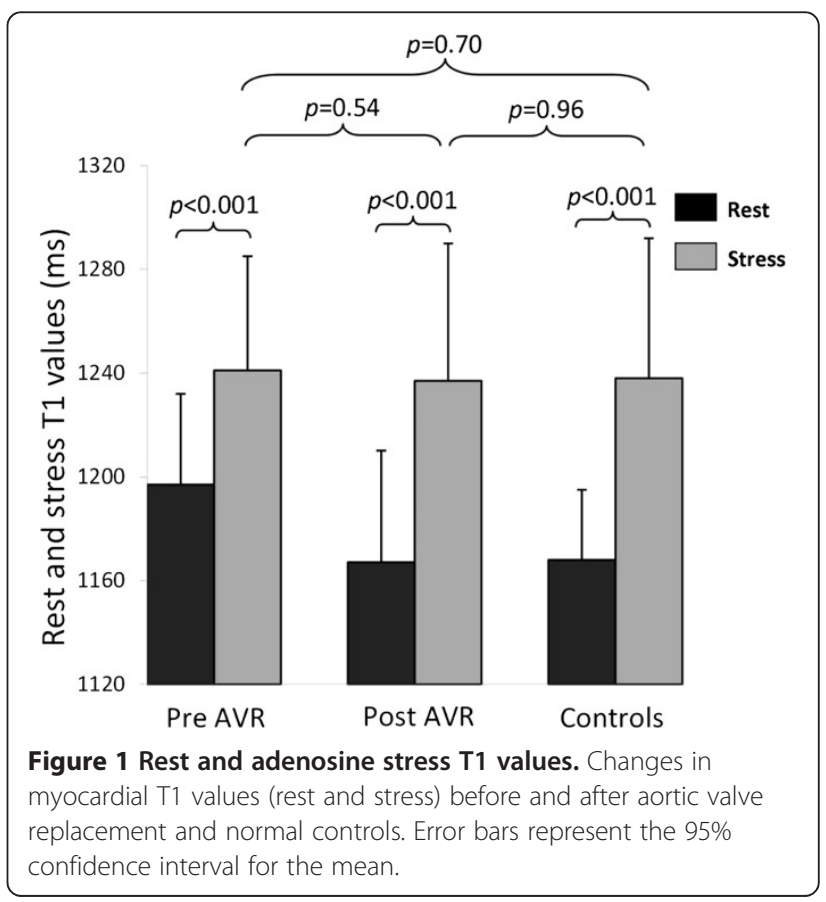




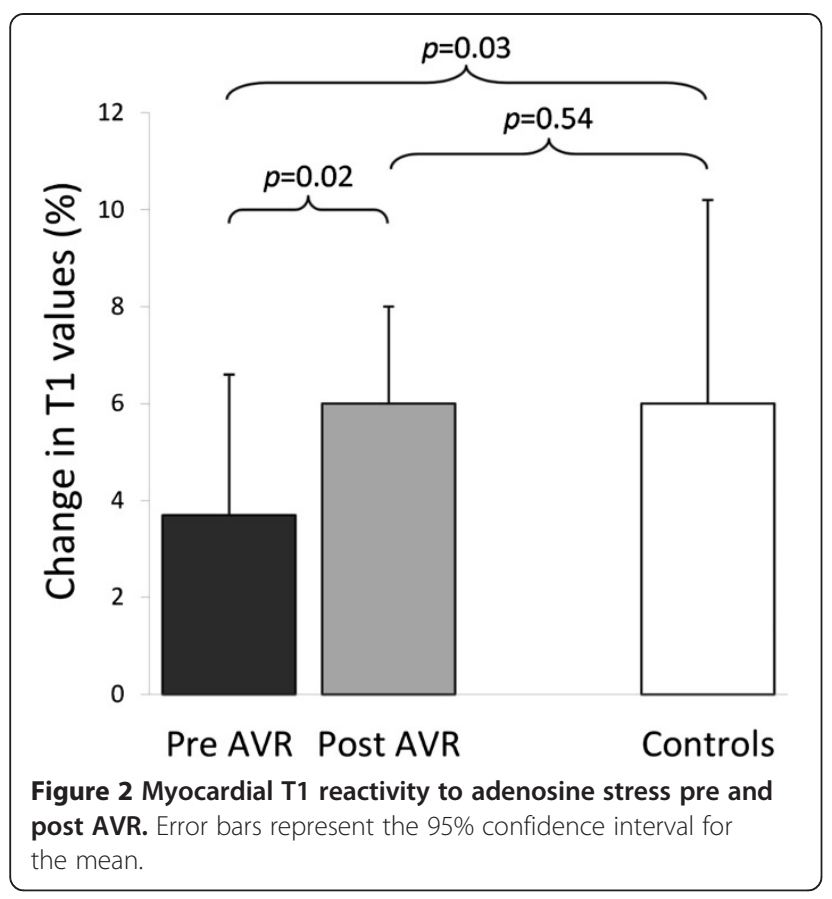

Figure 2 Myocardial T1 reactivity to adenosine stress pre and the mean.
post-AVR. We did not find a significant reduction in focal fibrosis (based on LGE\% of LV mass) post AVR, in line with a previous study [27]. Furthermore, others showed no significant diffuse fibrosis regression 6 months post AVR measured by equilibrium contrast [28]. These findings are hypothesis-generating, raising the possibility that, in severe AS, increased resting myocardial T1 may have a signal origin specifically in the intravascular compartment, rather than be explained solely by diffuse myocardial fibrosis in the interstitial compartment which we did not expect previously $[7,8]$ and also as suggested by others $[8,26,28]$. Increased resting coronary blood flow in severe AS as adaptation for the increased demands of the hypertrophied myocardium has previously been demonstrated [16,29-31], despite inadequate growth of vascular bed, characteristic of pressure overload hypertrophy [32].

\section{Influence of intravascular myocardial blood volume on myocardial $\mathrm{T} 1$ relaxation times}

T1-mapping is typically known for edema imaging and as a surrogate for diffuse myocardial fibrosis in the absence of other causes of interstitial expansion (such as edema and amyloidosis) [1], but in principle it measures global water content in tissue, whether intra-cellular,

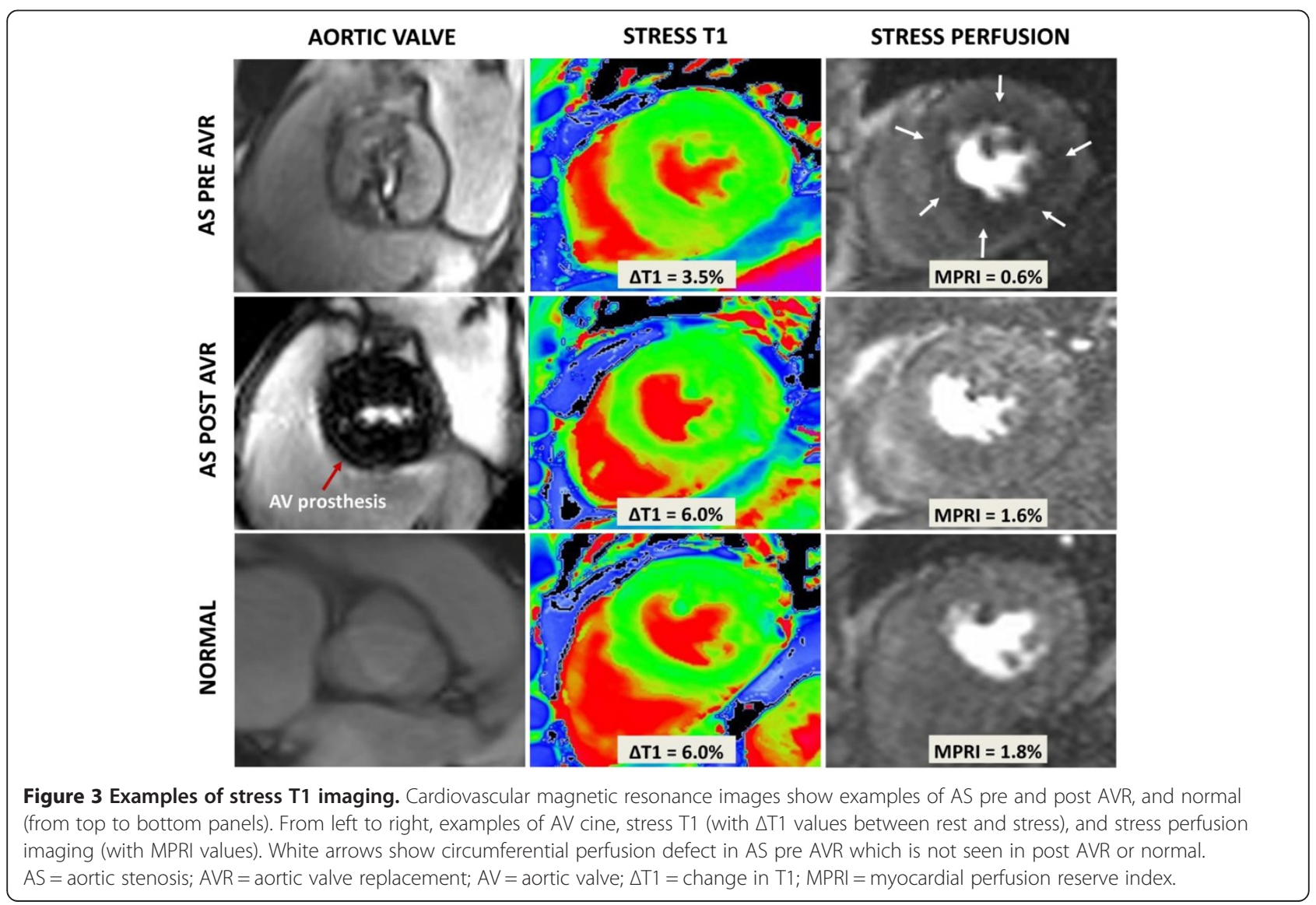


extra-cellular or intravascular. To our knowledge, the influence of intravascular myocardial blood volume and its dynamic changes on myocardial T1 has never been investigated previously. In this work we used a vasodilator stress agent, adenosine [33] to study directly the vascular compartment contribution to the native T1 in both normal and diseased conditions. We demonstrate for the first time a clear effect of the intravascular compartment during stress on myocardial T1 in normal controls and AS patients. The attenuated stress $\mathrm{T} 1$ response in severe AS may reflect reduced myocardial perfusion reserve in line with previous studies $[16,34]$. This observation paves way for coronary reserve assessments with stress T1-mapping as an alternate biomarker, free of intravascular administration of Gadolinium contrast, and insensitive to potential heart rate dependencies due to properties of the underlying T1 mapping technique [19].

\section{Diffuse myocardial fibrosis may not be the sole contributor to increased myocardial T1 and extracellular volume in severe AS}

The increased native T1 and ECV in AS is traditionally attributed to interstitial expansion due to diffuse fibrosis. However, if T1 changes were due to interstitial expansion and diffuse fibrosis only, then we would expect an increase in T1 values in AS both at baseline and during the stress due to presence of increased interstitial water. In contrast, we found that stress $\mathrm{T} 1$ values were similar for control and AS patients. The complete normalization of both resting $\mathrm{T} 1$ and vasodilator $\mathrm{T} 1$ response after AVR although the percentage of LV myocardium that shows focal fibrosis is unchanged indicates a significant role of the intravascular compartment in myocardial tissue pathology in AS. This concurs with a previous study by Eberli et al. who demonstrated markedly increased resting blood flow and reduced coronary flow reserve in aortic valve disease, but maximum flow during stress is similar to patients who had valve replacement and normal controls [30].

Figure 4 illustrates the proposed changes of the water compartment in the myocardial tissue of AS patients. This scenario is fully consistent with the interpretation of the impact of the reactive partial blood volume of blood, which has significantly more water content and a longer $\mathrm{T} 1$ than the mix of tightly packed myocytes separated by the true interstitial space. The effective myocardial T1 resulting from such simplified two-compartmental model can be expressed as: $[35,36]$.

$$
\begin{aligned}
& T 1_{\text {myocardium }} \sim P V_{\text {Blood }} . T 1_{\text {Blood }}+P V_{\text {Cells\&Interstitium }} . T 1_{\text {Cells\&Interstitium }} \\
& \mathrm{T} 1_{\text {blood }} \sim 1800 \mathrm{~ms} \text { at } 3 \mathrm{~T} \text { (own unpublished data) } \\
& \text { and } \mathrm{PV} \mathrm{blood}_{\text {blod }} \sim 10 \% \text { at rest } \\
& \mathrm{T} 1_{\text {cells\&interstitium }} \sim 1100 \mathrm{~ms}
\end{aligned}
$$

(to fit observed overall T1 in normal controls at rest)

The change in partial blood volume itself is hard to measure directly and is usually approximated as about a third of the corresponding change in the flow [37]. Assuming the maximal blood flow change in normal controls is about 3 fold [38], the normal resting blood volume in the myocardium should approximately double to $20 \%$ in normal controls with the respective simulated $\mathrm{T} 1$ reactivity $\sim 6 \%$, in excellent agreement with our observations. In AS patients before AVR, the same model implicates that the resting blood volume increased to $\sim 14 \%$, with respective flow response reduced to $\sim 110 \%$, in order to approximate the observed stress $\mathrm{T} 1$ reactivity at $\sim 3.5 \%$.

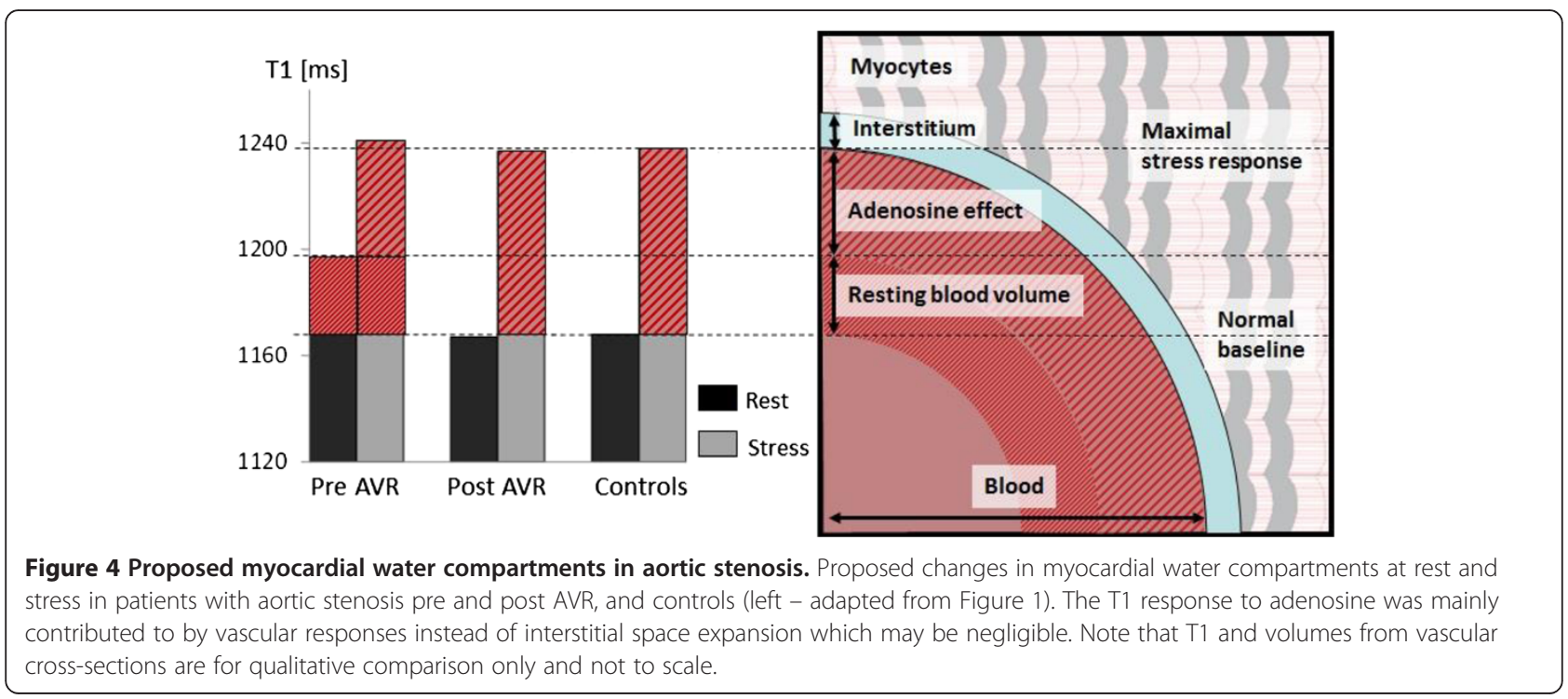


Our findings suggest that whenever adenosine stress is part of a CMR protocol that includes T1 mapping for ECV estimation, post contrast $\mathrm{T} 1$ should be acquired after a sufficient time has passed to ensure that myocardium is no longer in hyperemic state. Furthermore, our findings may also have important clinical implications as T1 changes in AS may serve as a marker for determining disease progress and therapeutic response, although this should be explored further in larger studies with a wider spectrum of AS severity.

\section{Study limitations}

Our study population was small in line with a proof of concept study, and therefore confirmation in larger scale studies is warranted. We performed a single mid-ventricular short-axis T1-map during stress, which represents a sample of the myocardium rather than the entire left ventricle; however we believe that the myocardial changes in severe AS are mostly homogenous, and this is therefore unlikely to affect the results. Although good agreement of normal resting myocardial $\mathrm{T} 1$ has been documented between ShMOLLI and MOLLI T1-mapping techniques [19], the numeric results in $\mathrm{T} 1$ in disease and $\mathrm{T} 1$ vascular reactivity may not hold between different methods where multiple parametric dependencies between T1, T2 and magnetization transfer (MT) in multiple tissue compartments may affect the effect size $[8,13,14,39,40]$. Further research is required to fully model the interaction between flow, volume and blood T1, which have been shown to be strongly stratified by vessel size in the brain, but not deeply studied in the heart [37].

\section{Conclusions}

Patients with severe aortic stenosis demonstrated increased resting myocardial $\mathrm{T} 1$ values, which correlated with aortic valve area, LVH and impaired myocardial perfusion reserve, but achieved the same maximal stress $\mathrm{T} 1$ response as healthy controls. The abnormal resting myocardial T1 and $\Delta \mathrm{T} 1$ stress response normalized seven months post-AVR without specific treatment towards regression of myocardial fibrosis. Our findings support the concept that the intravascular compartment is a significant contributor to myocardial T1 relaxation times, and provide a novel mechanism to explain the $\mathrm{T} 1$ changes previously only attributed to diffuse myocardial fibrosis in the interstitial compartment. Coronary reserve may be assessed using native $\mathrm{T} 1$-mapping and this may serve as an alternate biomarker for disease severity and therapeutic response in aortic stenosis.

\section{Abbreviations}

AS: Aortic stenosis; AVR: Aortic valve replacement; CMR: Cardiovascular magnetic resonance; ECV: Extracellular volume; FWHM: Full width half maximum; LGE: Late gadolinium enhancement; LVEF: Left ventricular ejection fraction; LVH: Left ventricular hypertrophy; LVMI: Left ventricular mass index; MPRI: Myocardial perfusion reserve index; ShMOLLl: Shortened modified look-locker inversion recovery; Sl: Signal intensity.
Competing interests

The authors declare that they have no competing interests.

\section{Authors' contributions}

MM contributed to the conception, design and coordination of the study, substantially acquired and analyzed the data, performed statistical analysis and drafted the manuscript; SKP provided the methods, data interpretation and significantly participated in drafting the manuscript; EL analysed T1 mapping data and critical revision of the manuscript; VMF contributed to data analysis concept, assisted with drafting and critical revision of the manuscript and JMF contributed to data acquisition and critical revision of the manuscript; AL contributed to data LGE analysis and critical revision of the manuscript; NP participated to the coordination of the study and critical revision of the manuscript; SD and HA critically revised the manuscript; SN and TDK contributed to the conception and design of the study and critically revised the manuscript.

\section{Acknowledgments}

We thank the Cardiothoracic Surgeons and the Pre-admission Clinic nurses, Oxford University Hospitals for their help with recruitment of patients. Dr Masliza Mahmod was funded by the National University of Malaysia and Ministry of Higher Education Malaysia. This work was supported by the British Heart Foundation (BHF; PG/08/101/26126) and by the Oxford NIHR Biomedical Research Centre. Professor Stefan Neubauer also acknowledges support from the BHF Centre of Research Excellence, Oxford. Dr Stefan Piechnik and Dr Vanessa Ferreira are supported by the National Institute for Health Research (NIHR) Oxford Biomedical Research Centre based at The Oxford University Hospitals Trust at the University of Oxford.

\section{Disclosures}

US patent pending 61/387,591: SKP. Piechnik et al. SYSTEMS AND METHODS FOR SHORTENED LOOK LOCKER INVERSION RECOVERY (Sh-MOLLI) CARDIAC GATED MAPPING OF T1. September 29, 2010. Licensed exclusively to to Siemens Medical.

\section{Author details}

${ }^{1}$ University of Oxford Centre for Clinical Magnetic Resonance Research (OCMR), Division of Cardiovascular Medicine, Radcliffe Department of Medicine, John Radcliffe Hospital, Oxford OX3 9DU, UK. ${ }^{2} 1$ st Department of Cardiology, AHEPA Hospital, Aristotle University of Thessaloniki, Thessaloniki 54636, Greece.

Received: 7 July 2014 Accepted: 4 November 2014

Published online: 20 November 2014

\section{References}

1. Moon JC, Messroghli DR, Kellman P, Piechnik SK, Robson MD, Ugander M, Gatehouse PD, Arai AE, Friedrich MG, Neubauer S, Schulz-Menger J, Schelbert EB. Myocardial T1 mapping and extracellular volume quantification: a Society for Cardiovascular Magnetic Resonance (SCMR) and CMR Working Group of the European Society of Cardiology consensus statement. J Cardiovasc Magn Reson. 2013; 15:92.

2. Ugander M, Bagi PS, Oki AJ, Chen B, Hsu LY, Aletras AH, Shah S, Greiser A, Kellman P, Arai AE. Myocardial edema as detected by pre-contrast T1 and T2 CMR delineates area at risk associated with acute myocardial infarction. J Am Coll Cardiol Img. 2012; 5:596-603.

3. Messroghli DR, Niendorf T, Schulz-Menger J, Dietz R, Friedrich MG. T1 mapping in patients with acute myocardial infarction. J Cardiovasc Magn Reson. 2003; 5:353-59.

4. Dongaonkar RM, Stewart RH, Quick CM, Uray KL, Cox CS Jr, Laine GA. Award article: Microcirculatory Society Award for Excellence in Lymphatic Research: time course of myocardial interstitial edema resolution and associated left ventricular dysfunction. Microcirculation (New York, NY: 1994). 2012; 19:714-22

5. Ferreira VM, Piechnik SK, Dall'Armellina E, Karamitsos TD, Francis JM, Ntusi N, Holloway C, Choudhury RP, Kardos A, Robson MD, Friedrich MG, Neubauer S. T(1) mapping for the diagnosis of acute myocarditis using CMR: comparison to T2-weighted and late gadolinium enhanced imaging. J Am Coll Cardiol Img. 2013; 6:1048-58. 
6. Ferreira VM, Piechnik SK, Dall'Armellina E, Karamitsos TD, Francis JM, Choudhury RP, Friedrich MG, Robson MD, Neubauer S. Non-contrast T1-mapping detects acute myocardial edema with high diagnostic accuracy: a comparison to T2-weighted cardiovascular magnetic resonance. J Cardiovasc Magn Reson. 2012; 14:42.

7. Dass S, Suttie JJ, Piechnik SK, Ferreira VM, Holloway CJ, Banerjee R, Mahmod M, Cochlin L, Karamitsos TD, Robson MD, Watkins H, Neubauer S. Myocardial tissue characterization using magnetic resonance noncontrast $\mathrm{t} 1$ mapping in hypertrophic and dilated cardiomyopathy. Circulation Cardiovascular imaging. 2012; 5:726-33.

8. Bull S, White SK, Piechnik SK, Flett AS, Ferreira VM, Loudon M, Francis JM, Karamitsos TD, Prendergast BD, Robson MD, Neubauer S, Moon JC, Myerson SG. Human non-contrast T1 values and correlation with histology in diffuse fibrosis. Heart. 2013; 99:932-37.

9. Karamitsos TD, Piechnik SK, Banypersad SM, Fontana M, Ntusi NB, Ferreira VM, Whelan CJ, Myerson SG, Robson MD, Hawkins PN, Neubauer S, Moon JC. Noncontrast T1 mapping for the diagnosis of cardiac amyloidosis. J Am Coll Cardiol Img. 2013; 6:488-97.

10. Sado DM, White SK, Piechnik SK, Banypersad SM, Treibel T, Captur G, Fontana M, Maestrini V, Flett AS, Robson MD, Lachmann RH, Murphy E, Mehta A, Hughes D, Neubauer S, Elliott PM, Moon JC. Identification and assessment of Anderson-Fabry disease by cardiovascular magnetic resonance noncontrast myocardial T1 mapping. Circulation Cardiovascular imaging. 2013; 6:392-98.

11. Pedersen SF, Thrysoe SA, Robich MP, Paaske WP, Ringgaard S, Botker HE, Hansen ES, Kim WY. Assessment of intramyocardial hemorrhage by T1-weighted cardiovascular magnetic resonance in reperfused acute myocardial infarction. J Cardiovasc Magn Reson. 2012; 14:59.

12. Messroghli DR, Walters K, Plein S, Sparrow P, Friedrich MG, Ridgway JP, Sivananthan MU. Myocardial T1 mapping: application to patients with acute and chronic myocardial infarction. Magn Reson Med. 2007; 58:34-40.

13. Robson MD, Piechnik SK, Tunnicliffe EM, Neubauer S. T measurements in the human myocardium: The effects of magnetization transfer on the SASHA and MOLLI sequences. Magn Reson Med. 2013; 70:664-70.

14. Gai ND, Stehning C, Nacif M, Bluemke DA. Modified Look-Locker T1 evaluation using Bloch simulations: human and phantom validation. Magn Reson Med. 2013; 69:329-36.

15. Fullerton GD, Ord VA, Cameron IL. An evaluation of the hydration of lysozyme by an NMR titration method. Biochim Biophys Acta. 1986; 869:230-46.

16. Rajappan K, Rimoldi OE, Dutka DP, Ariff B, Pennell DJ, Sheridan DJ, Camici PG. Mechanisms of coronary microcirculatory dysfunction in patients with aortic stenosis and angiographically normal coronary arteries. Circulation. 2002; 105:470-76.

17. Vahanian A, Alfieri O, Andreotti F, Antunes MJ, Baron-Esquivias G, Baumgartner H, Borger MA, Carrel TP, De Bonis M, Evangelista A, Falk V, lung B, Lancellotti P, Pierard L, Price S, Schafers HJ, Schuler G, Stepinska J, Swedberg K, Takkenberg J, Von Oppell UO, Windecker S, Zamorano JL, Zembala M. Guidelines on the management of valvular heart disease (version 2012). Eur Heart J. 2012; 33:2451-96.

18. Karamitsos TD, Hudsmith LE, Selvanayagam JB, Neubauer S, Francis JM. Operator induced variability in left ventricular measurements with cardiovascular magnetic resonance is improved after training. J Cardiovasc Magn Reson. 2007; 9:777-83.

19. Piechnik SK, Ferreira VM, Dall'Armellina E, Cochlin LE, Greiser A, Neubauer S, Robson MD. Shortened Modified Look-Locker Inversion recovery (ShMOLLI) for clinical myocardial T1-mapping at 1.5 and 3 T within a 9 heartbeat breathhold. J Cardiovasc Magn Reson. 2010; 12:69.

20. Karamitsos TD, Leccisotti L, Arnold JR, Recio-Mayoral A, Bhamra-Ariza P, Howells RK, Searle N, Robson MD, Rimoldi OE, Camici PG, Neubauer S, Selvanayagam JB. Relationship between regional myocardial oxygenation and perfusion in patients with coronary artery disease: insights from cardiovascular magnetic resonance and positron emission tomography. Circulation Cardiovascular imaging. 2010; 3:32-40.

21. Selvanayagam JB, Jerosch-Herold M, Porto I, Sheridan D, Cheng AS, Petersen SE, Searle N, Channon KM, Banning AP, Neubauer S. Resting myocardial blood flow is impaired in hibernating myocardium: a magnetic resonance study of quantitative perfusion assessment. Circulation. 2005; 112:3289-96.

22. Kellman $\mathrm{P}$, Arai AE, McVeigh ER, Aletras AH. Phase-sensitive inversion recovery for detecting myocardial infarction using gadolinium-delayed hyperenhancement. Magn Reson Med. 2002; 47:372-83.
23. Nagel E, Klein C, Paetsch I, Hettwer S, Schnackenburg B, Wegscheider K, Fleck E. Magnetic resonance perfusion measurements for the noninvasive detection of coronary artery disease. Circulation. 2003; 108:432-37.

24. Flett AS, Hasleton J, Cook C, Hausenloy D, Quarta G, Ariti C, Muthurangu V, Moon JC. Evaluation of techniques for the quantification of myocardial scar of differing etiology using cardiac magnetic resonance. J Am Coll Cardiol Img. 2011; 4:150-56

25. Moon JC, Treibel TA, Schelbert EB. T1 mapping for diffuse myocardial fibrosis: a key biomarker in cardiac disease? J Am Coll Cardiol. 2013; 62:1288-89.

26. Mewton N, Liu CY, Croisille P, Bluemke D, Lima JA. Assessment of myocardial fibrosis with cardiovascular magnetic resonance. J Am Coll Cardiol. 2011; 57:891-903.

27. Weidemann F, Herrmann S, Stork S, Niemann M, Frantz S, Lange V, Beer M Gattenlohner S, Voelker W, Ertl G, Strotmann JM. Impact of myocardial fibrosis in patients with symptomatic severe aortic stenosis. Circulation. 2009; 120:577-84.

28. Flett AS, Sado DM, Quarta G, Mirabel M, Pellerin D, Herrey AS, Hausenloy DJ, Ariti C, Yap J, Kolvekar S, Taylor AM, Moon JC. Diffuse myocardial fibrosis in severe aortic stenosis: an equilibrium contrast cardiovascular magnetic resonance study. European heart journal cardiovascular Imaging. 2012; 13:819-26.

29. Burwash IG, Lortie M, Pibarot P, de Kemp RA, Graf S, Mundigler G, Khorsand A, Blais C, Baumgartner H, Dumesnil JG, Hachicha Z, DaSilva J, Beanlands RS. Myocardial blood flow in patients with low-flow, low-gradient aortic stenosis: differences between true and pseudo-severe aortic stenosis. Results from the multicentre TOPAS (Truly or Pseudo-Severe Aortic Stenosis) study. Heart. 2008; 94:1627-33.

30. Eberli FR, Ritter M, Schwitter J, Bortone A, Schneider J, Hess OM, Krayenbuehl HP. Coronary reserve in patients with aortic valve disease before and after successful aortic valve replacement. Eur Heart J. 1991; 12:127-38.

31. Marcus ML, Doty DB, Hiratzka LF, Wright CB, Eastham CL. Decreased coronary reserve: a mechanism for angina pectoris in patients with aortic stenosis and normal coronary arteries. N Engl J Med. 1982; 307:1362-66.

32. Marcus ML, Koyanagi S, Harrison DG, Doty DB, Hiratzka LF, Eastham CL. Abnormalities in the coronary circulation that occur as a consequence of cardiac hypertrophy. Am J Med. 1983; 75:62-6.

33. Pennell DJ. Cardiovascular magnetic resonance and the role of adenosine pharmacologic stress. Am J Cardiol. 2004; 94:26D-31D. discussion 31D-32D.

34. Steadman CD, Jerosch-Herold M, Grundy B, Rafelt S, Ng LL, Squire IB, Samani NJ, McCann GP. Determinants and functional significance of myocardial perfusion reserve in severe aortic stenosis. J Am Coll Cardiol Img. 2012; 5:182-89.

35. Piechnik S, Ferreira V, Lewandowski A, Ntusi N, Banerjee R, Holloway C, Hofman M, Sado D, Maestrini V, White S, Lazdam M, Karamitsos T, Moon J, Neubauer $\mathrm{S}$, Leeson $\mathrm{P}$, Robson M. Normal variation of magnetic resonance T1 relaxation times in the human population at $1.5 \mathrm{~T}$ using ShMOLLI. J Cardiovasc Magn Reson. 2013; 15:13.

36. Canty JM Jr, Judd RM, Brody AS, Klocke FJ. First-pass entry of nonionic contrast agent into the myocardial extravascular space. Effects on radiographic estimates of transit time and blood volume. Circulation. 1991; 84:2071-78.

37. Piechnik SK, Chiarelli PA, Jezzard P. Modelling vascular reactivity to investigate the basis of the relationship between cerebral blood volume and flow under CO2 manipulation. Neurolmage. 2008; 39:107-18.

38. Czernin J, Muller P, Chan S, Brunken RC, Porenta G, Krivokapich J, Chen K, Chan A, Phelps ME, Schelbert HR. Influence of age and hemodynamics on myocardial blood flow and flow reserve. Circulation. 1993; 88:62-9.

39. Messroghli DR, Greiser A, Frohlich M, Dietz R, Schulz-Menger J. Optimization and validation of a fully-integrated pulse sequence for modified looklocker inversion-recovery (MOLLI) T1 mapping of the heart. J Magn Reson Imaging. 2007; 26:1081-86.

40. Chow K, Flewitt JA, Green JD, Pagano JJ, Friedrich MG, Thompson RB. Saturation recovery single-shot acquisition (SASHA) for myocardial T(1) mapping. Magn Reson Med. 2014; 71:2082-95.

\section{doi:10.1186/s12968-014-0092-y}

Cite this article as: Mahmod et al:: Adenosine stress native T1 mapping in severe aortic stenosis: evidence for a role of the intravascular compartment on myocardial T1 values. Journal of Cardiovascular Magnetic Resonance 2014 16:92. 